\title{
Dealing with Mental Health in Online Learning: A Retrospect on ELT Teachers and EFL Learners during COVID-19 Pandemic
}

\author{
Asma-Ul-Ferdous ${ }^{1}$ \& Nazia Forhin Shifat ${ }^{2}$ \\ ${ }^{1}$ ASA University. Dhaka. Bangladesh \\ ${ }^{2}$ Notre Dame University, Dhaka. Bangladesh \\ nazia@ndub.edu.bd
}

\author{
ARTICLE HISTORY \\ Received : 2020-10-16 \\ Revised : 2020-11-01 \\ Accepted :2020-12-13
}

\section{KEYWORDS}

Pandemic

Mental health

English Language Teaching (ELT)

English as Foreign Language (EFL)

\begin{abstract}
This paper intends to depict the mental health of English Language Teaching (ELT) teachers and English as Foreign Language (EFL) learners at a tertiary level during the COVID-19 pandemic. The educational boards across the globe have been forced to transition to smart classrooms, digital platforms, and effective teacher training programs in online delivery methods. In Bangladesh, the networking system and the management system are being run with care to ensure online classes at tertiary levels. This study showed how ELT teachers and EFL learners experience diverse and innumerable inconveniences due to geographical locations, finance and other systematic online education problems during the pandemic. The study found results which showed what makes them susceptible to anxiety, frustration, depression, which injure their mental health. Getting habituated to new study techniques, cooperating with the lack of laboratories and other required study materials, network connectivity problems, and the harshness of COVID-19 make their living challenging and unneeded mental stress. Quantitative data has been collected through Google questionnaire, and qualitative data has been collected through semi-structured interviews over telephone and online messaging. The results showed that despite continually searching for a way to overcome various troubles, teachers and students get drown into worsening mental health.
\end{abstract}

\section{Introduction}

The world is currently facing unprecedented pandemic. There is no doubt the Covid-19 has affected our way of living and has disrupted the normal cycle the world has been revolving on for the past few decades. Along with the economy, society, political system, governance mechanism, the COVID-19 has also shown its obtrusive impact on the education system. The situation turned much difficult as students and teachers were not prepared for the online platform at all. When the whole world is fighting with this sudden outbreak, Bangladesh got the first COVID-19 case on March 8, 2020 (Satu et al., 2020). The World Health Organization (WHO) has declared the COVID19 pandemic is as an international public health emergency (World Health Organization, 2020).

Henceforth, the integral constituent of this field is the teachers and students. As the pandemic COVID-19 has transformed teaching-learning to a newer mood, the pedagogy must be reorganized to change learners' perspectives and the best outcome (Islam \& Bhuiyan, 2020). However, e-learning protocol cannot change the pandemic itself but can ensure social distancing by limiting face-to-face communications (Murphy, 2020).
The virus has taken this system to the limit on them. As the long followed scheme turns out to be an aberration; the vital resources and support networks also comes to a halt. Alongside the day to day lives of the teachers and students and their mental health is also affected. Some questions quickly come to mind: While the experts throughout the world come together to find solutions on different academic and administrative issues, how much is the mental aspect considered? How much are the taken steps beneficial for the developing country like Bangladesh? The majority of the students, especially pupils living in developing countries, tend to score the highest possible grade. Most of them consider it to be the only important thing in life. However, the concept of mental well-being remains concealed and unnoticed by parents and teachers.

As the whole world combats for a physical cure from this outbreak, mental health is negligent (Usman et al., 2020). Usually, psychological diseases such as dementia, schizophrenia, or bipolar disorder are considered serious problems. Based on traditional belief, a student is mentally healthy if s/he is not suffering from such diseases. According to Mowbray (2020), mental health during the COVID-19 pandemic is related to occupation, gender, socioeconomic status 
and so on. Moreover, the absence of mental illness and emotional health refers to a positive mind that gives someone the ability to laugh to carry on daily lives. People who have good health can still have underlying emotional problems and mental problems. A mental health problem's negativity can hinder the individuals' natural potentialities in early education, work, and become unsociable. Teachers and students of universities come from various social backgrounds, and they are superstitious about their mental health. However, the challenge of online teaching and learning is a grey area that needs to be carefully thought.

In Bangladesh, anxiety and depression are prevalent among tertiary level students. Nevertheless, online classes' onset due to the pandemic has imposed an extra burden of mental stress and rational fears of certain uncertainties on both students and teachers. Teachers who teach English as a foreign language or second language in various private universities and learners are positively affected due to COVID-19. It requires a great deal of motivation energy to teach and learn English. According to Saqlain \& Islam (2014), the goal of second language learning is both linguistics and non-linguistic where it focuses not only on individual's ability of reading, writing, speaking and listening but also on the eagerness and motivation to learn the language. Although the people worldwide can conduct a successful meeting or online class with transparent, placid sound systems, the meticulous uninterrupted real-time streaming is unknown to many and Bangladesh. For a third world or developing country, the approach made to run online classes for preventing the academic sector from coming to an ultimate stoppage is very challenging. In this regard, Dhawan (2020) has mentioned that online pedagogy is related to the accessibility, affordability, leniency, policies and long-lasting learning.

The study has been conducted with several objectives. These are to focus and emphasize mental health ideals and diagnose what remarkable changes private university ELT teachers and EFL learners go through to transform the existing educational system into a modern scientific model of online education. As background conception, it has been kept in mind that mental happiness plays a crucial role in the gradual rise of virtual academic progress. In Bangladesh, as the novel epidemic virus soon takes the shape of a pandemic form like all the other countries, it was quite challenging to imagine the unimaginable to figure out solutions to unpredictable events, where experience does not exist to bring a solution. According to the traditional education system, the teacher enters; Students rise; the teacher takes attendance, and the class starts. Here, interaction occurs through face-toface communication. After the COVID-19 lockdown in Bangladesh, some of the Universities opted for online classes, and the majority of the students go back home. However, things turned out of the frying pan and into the fire for both the teachers and students. The traditional class system has suddenly changed into a virtual class scheme. Lack of face to face interaction causes both the teachers and students more anxious. It makes them worried about the important lessons they are missing. All these facts make online classes a sheer challenge to reach out to individual students scattered all over the country in this current situation. According to Tasneem (2020), shifting to online classes will be inconvenient to the students of lower-income families because they do not have the necessary technological devices and internet connections. As a result, gradually, both teachers and learners get mentally stressed and frustrated. In rural areas, e-learning is worse than rural areas because of insufficient infrastructure required in virtual classes (Radha et al., 2020).

\section{Literature Review}

Several studies have been conducted to show the impacts of COVID-19 on students and teachers' mental health. Many studies have revealed how learners and teachers from various backgrounds are severely affected by the extended time lockdown due to pandemic. As online classroom has taken the place of the traditional classroom in current pandemic, numerous studies worldwide have been conducted on the impacts of covid-19 on various aspects like economy, education, health etc. To continue remote learning with a collaborative effort, impromptu dependency on the online network has made researchers and practitioner examine whether people are psychically and mentally placid or not. The rapid transition to online learning has made the teachers and students wholly dependent on technological devices to cope with academic activities in education.

In Bangladesh, private universities are going with online activities to their site where public institutions are still waiting to start. Therefore, the mental health of both ELT teachers and EL learners of the private universities is being overlooked in where it lies the rationale of conducting this research. MacIntyre et al. (2020) conducted a study on 600 language teachers and showed the stressors and coping responses among the language teachers in the advent of Covid-19. Many researchers have conducted a study of the impact of Covid-19 on teacher's psychology and emotions. Besser, Lotem, Zeigler (2020) in their study showed a higher level of psychological stress on university teachers of Israel during the transiting to online synchronous teaching. Their ultimate goal was to illustrate the impact that falls not only on students but also on university professors.

Recent researches (Priyo \& Hazra, 2020) showed that about 21 per cent of the students represent severe mental health concerns and 40 per cent suffer from mild mental health concerns. In their study, Banna et 
al. (2020) have found out the mental health condition of 1,427 adult people from Bangladesh during the pandemic. They have shown $33.7 \%$ in anxiety symptom, $57.9 \%$ in depressive symptom $59.7 \%$ in mild to too severe level of stress. Hasan et al. (2020) have extracted results from their study on mental health \& well-being among home quarantined Bangladeshi students. It is shown that $28.5 \%$ of the respondents had stress, $33.3 \%$ anxiety, $46.92 \%$ depression from mild to too severe, and according to DASS 21 and $69.31 \%$ had event-specific distress from mild to severe in terms of severity according to IES. Hossain et al. (2020) from Bangladesh have conducted a study of Bangladesh's people's mental health condition. Islam et al. (2020) explored a study on covid-19 related stress and its factors and found that $85.60 \%$ of the participants are in COVID-19-related stress, resulting in sleep shortness and short temper chaos in the family. Nevertheless, Yeasmin et al. (2020) in their study have investigated how COVID19 has impacted on children's mental health in Bangladesh where they show that $43 \%$ children suffer from a major depressive disorder and $30.5 \%$ suffered from the mild disorder, $19.3 \%$ from moderate disorder and $7.2 \%$ from severe disturbances.

Huge research has been done on the impacts of covid-19 on the mental health of diversified participants worldwide. Studying relevant literature, it is found that none of the studies covers what mental trauma English language teachers and students from the private universities of Bangladesh embrace during online classes. The sporadic study has been conducted in Bangladesh during covid-19 on student's and teachers' mental and psychical health, whereas almost none on ELT teachers and EL learners. Though some mental health studies have been carried on other sectors' participants, very few are conducted on the teachers and students from education sectors. These urge the researcher what mental issues the students and teachers of English language embrace in online learning and teaching during COVID-19. It is hoped that this study will help future researchers do further study on the private and public university's students and teachers' mental health and pave the way how this mental fugitiveness can be reduced to a certain extent.

\section{Method}

The study was conducted among the students and teachers of private universities of Bangladesh. The mixed-method combines qualitative and quantitative approaches in the data collection process. Data was collected through interviews over the phone, messaging and Google questionnaire. All the participants, including teachers and students, were selected randomly from the English department who was adjusting to online learning during the pandemic and spent at least one trimester online. Respondents for the interviews included ten EFL (English as Foreign Language) learners from a private university of Bangladesh and ten ELT teachers from different private universities in Bangladesh. Quantitative data regarding stress and anxiety related to e-learning was collected from 46 participants from various private universities in Dhaka's capital. The participants were ESL/EFL learners from various private universities. A Questionnaire having 13 questions was sent to these 46 respondents through Google questionnaire to collect data. Quantitative data were analysed using percentage and shown descriptively.

\section{Findings and Discussion}

In the survey when participants were asked whether they feel stressed and anxious about their online learning where $70 \%$ replied 'extremely' and $10 \%$ said 'medium' and rest $20 \%$ replied that they are not stressed and anxious at all where nobody was in 'lower' anxiety. In query to the availability of devices majority participants $(82.2 \%$, the aggregated result of 'agree' and 'strongly agree) agreed that they have logistic support like Wi-Fi, laptop, internet for online learning. Among them, $76.1 \%$ of students use a smartphone, $37 \%$ use laptops, and only $2.2 \%$ use a desktop as an online learning device during COVID19. About internet connection, only $26.1 \%$ found it fast. The same proportionate $37 \%$ of participants found it interrupted and slow where none says that it is speedy. Mondol and Mohiuddin (2020) from Bangladesh in their study, showed why teachers and students asked for cost-effective data packages during the pandemic. When they were asked if it is affordable to attend online classes during this pandemic the same proportionate $41 \%$ the aggregated result of 'strongly agree' and 'agree' agreed on it, in opposite aggregated $29.5 \%$ disagreed on it were $29.55 \%$ remained neutral. In responses to the overall question whether they can enjoy online classes, only $34.8 \%$ agreed that they enjoy it where aggregated $37 \%$ disagreed with this. In response to whether their home environment is suitable for online learning or not, the participants of equal proportionate, $41.3 \%$, were in favour and against it, whereas the remaining participants were neutral.

Furthermore, as participants were asked about their progress in English communication skills, (48.9\% the aggregated result of 'strongly disagree' and 'disagree') replied that they were not in progress where only $26.7 \%$ agreed it that they were developing language skills. In another query, participants were asked about the reliability of online assessments where to $50 \%$ responders, the online assessment is reliable. In against, only to $19.6 \%$ responders, the online assessment does not seem valid and reliable like offline examination. "The validity and reliability of such unsupervised online exams can be improved by conducting more of exams with different possible questions with varying time duration on the same topic instead of conducting one single exam for evaluation" (Zayapragassarazan, 2020). 
Furthermore, when they were asked whether they can afford internet or not $60.5 \%$. The aggregated result of 'extremely difficult' and 'difficult' said it was difficult to afford and the aggregated rest replied that they can afford it and can manage it somehow. In another query, it was asked whether they could attend online classes quickly where the result says that $70.5 \%$ can attend somehow though sometimes they get disconnected but rest said they could quickly get access to online classes. In another query, 54.3\% responded that they could easily collect materials using the internet, but $17.4 \%$ replied that they could not quickly collect them. However, in another question, most $80 \%$ agreed that reading those materials online or reading from soft copies makes them psychically exhausted and mentally tired where only $20 \%$ replied 'no'. To get more information on the teacher's mental health regarding the complete dependency online, 20 participants were interviewed to add more data on quantitative data.

\subsection{Insufficient Logistics Along with Taxonomy in Status}

Students studying in universities come from different geographical locations of Bangladesh. Many of them are currently living outside Dhakatill now. Bangladesh, a developing country still has to work in the network services and other modern living facilities in the rural and remote areas. Whilst students and teachers living in the city centres manage to take the maximum benefit, people in rural areas struggle the most. Sufficient broadband network intensity and necessary devices to access online classes are few and far between too many. During the lockdown, the students from low-income family could not afford a laptop or desktop.

In contrast, mobile phones were not compelling enough for the participation of online classes. During this lockdown period, the learners were struggling with economic problems (Mishra et al., 2020). These teachers and students usually find it challenging to run and attend classes due to poor network connections and devices' unavailability.

It forges anxiety, worries, and restlessness in them. It goes same with the findings from the researcher (Islam et al. 1 2020) who have found out in their surveys that only $55.3 \%$ of people have access to laptops, PCs, or tablets to online classes and other $44.7 \%$ of the students cannot attend classes due to lack of logistics. Disruptions in internet connections due to load shedding, climate, and insufficient feasibility of devices, interrupt ongoing classes and make teachers and students mentally agitated. Materials scarcity and materials design is another issue during online lessons. To add more information on quantitative data in an interview regarding materials, a teacher replied, "If you ask about materials scarcity, I must say that there it is, and it was always there.
Moreover, all the teachers are well aware of this crisis and accustomed to dealing with that issue. A student said, "Teachers get a limited number of times to finish the syllabus because the syllabus is full of same old traditional contents. Teachers skip many important points just to finish the syllabus."

As a result of these fears, questions and feelings of being downgraded and unprivileged accumulated in them; they devastatingly feel broken, affecting their mental health. They worry that they would thus lack the necessary and competent knowledge that shortly will harm their grades and even professional life. Moreover, these students cannot wrap up their incomprehension of the concept, by browsing net and videos as supplements to their practical demands.

The unjustified feeling of insecurity arising in them cannot also be thrown down. They often feel that others who live in cities with better internet access and better computerized electronic devices would benefit. It injures their mentality and way of thinking. Learners often feel belittled among peers. Besides, it also widens the inequalities in access to learning that are already prevalent in our tertiary education level.

\subsection{Challenges in Implementation}

Although the authorities are taking initiatives to continue the semesters and finish the ongoing semester without much delay, some aspects need a brilliant move. Although the smartphone is ubiquitous among students, the smaller size is not good enough to understand the current study's online deliveries. In the interview, eight students who already attended online exams opined that they are not getting sufficient time to complete their assessment compared to classroom assessment in current practice. Adanır et al. (2020) found Turkish students' opinions where they showed their significant concerns of online assessment over its implementation where they showed worry for adopting cheating during the examination.

\subsection{Challenges in Other Sides}

The other big challenge is for the private university teachers and students doing part-time jobs. In this study, when the ten teachers were asked whether they are worried about losing their job, most of them showed their worry, and the students replied in the same way. It is also supported by the study of (Prio \& Hazra, 2020) where it has been shown that 42 per cent of the upperclassmen were found to have some form of income-generating occupations or even stable jobs to support themselves and their families.

Therefore, as lockdowns were urged throughout the country, many have lost their jobs or experienced a decrease in income. Many of them who still manage some form of income promoting sources face hindrances in coping with the duty and online class timings, increasing agitation in them. 


\subsection{Teachers' Maintaining Issues}

Another side of the struggle is studied on the teachers. In a question of how they maintain their sudden extra fare in reply, it is found that most of the teachers were not also prepared for the instituted online classes and assessment method. Although the adjustment to virtual classes has been quite successful for most universities in the developed nations, which already had the necessary technological infrastructure in place for assisting this shift, it has proven to be a challenging task in our country which did not have much prior experience in teaching courses online.

They had to adopt a completely new system they are barely used to in a short time. Often, the students feel a lack of being skilled in this platform of teaching and learning. Some face problems because they either lacked computer literacy or could not choose online platforms when they thought about net speed and device access to themselves and their students. They had to prepare new digital study notes and presentations and restructure their teaching to get it manageable and comprehensible. Despite the absence of lab and other various teaching equipment, teachers feel restive to ensure learning. Thus, teachers too have to comply and deal with the increased workload, mental stress, and frustrations on their insides. This pandemic to balance between personal and professional life is challenging for many teachers because staying at home creates a physical and psychological gap between home and school (MacIntyre et al., 2020).

Moving away from the face to face communication meant a lack of interactions. Self-doubt develops as educators consistently encounter the thoughts of not conveying their utmost to the students. Many teachers never feel comfortable with the online platform because they feel it is essential to see the students' smiley face in the flesh. A teacher said, "Online class or other activities seems to my food without salt. But, as I was professionally obliged to take online classes, I learn something new, get used to it and start organizing online classes with my students." They also have to grapple with the disruption of the ongoing class. Most of the time, it is inscrutable that all the assigned students are participating in the class with proper attention. The teacher said, "I strongly believe that online class and other activities should remain allowed even in other time except for pandemic because we must have the technological knowledge to arrange them." Some other teachers claimed before organizing the online classes they just started feeling a little bit stressed thinking that everything would go on "okay" or not.

Though, in a few days, they started to feel comfortable with the virtual classes. Another private university teacher shared his experience and said, "There are many drawbacks with online classes before/ during/ after time. Many students from various levels, who have more or less technological knowledge, aware of using apps or other media essential for an online class, are less interested and less stressed in attending the classes. This scenario is different for many students who do not know how to install or use the apps, making them stressed. Taking all the teachers' inconveniences and mental aspects into account, teachers happen to lost control of their patience and end up rebuking students on odd occasions, sometimes. It gives rise to turmoil and turbulent feelings in teachers' minds to what they feel sorry for soon after.

Teachers' mental health worsens when issues like salary, promotion, bonus, and allowance are unsettled in the current crisis. The situation gets critical because many things start going wrong due to the continuity of the pandemic lockdown. According to a private University "dealing with too many students creates a total mess sometimes. Online teaching and assessment method is difficult for many of the teachers.

Moreover, teaching numerous students with numerous problems with a new system is another big trouble. Many of the teachers feel unbearable stress which needs counselling and break from work." Another teacher said, "When you have to adjust with a new system, of course, you will feel lack of skill. Sometimes I share my incomplete skills with my colleagues, and we work as a team to have a clear concept of the new teaching method. Notably, the "mental health worsens when the bosses too do not know what to do and deduct the salary." Behind this scenario, some teachers feel relief just focusing on the present, not in the past and future.

\subsection{Stress during Online Exam}

The other big challenge is online exams, as exam designing is an important issue. According to Islam et al. (2020), online assessment with an open book can be successful and feasible if appropriately monitored but still showed worry whether it will work or not and emphasized the teacher's hard work in this regard.

Though some developed countries have the success of implementing online examinations, in developing countries, learners face challenges like lower computer literacy, limited access to ICT or lack of experiences that require learners to accept online mood of assessment (Adanır et al., 2020). Disagreement over admission tests and modes of evaluation has taken precedence over more important issues that can have long-term detrimental impacts on education. It drains the teachers, as they always figure out a path to negotiate with the authority and the student body. To get rid of all the negative energies in mind, and keep up with the workflow, teachers usually adhere themselves to works, escapes frequent dissentient standings, and engage in religious activities. 


\section{Conclusion}

As in Bangladesh covid-19 was detected in the mid of March, private universities adopted few initiatives to run their academic activities online. This study found that worsening mental health condition was embraced both by ELT teachers and EFL learners. The study reveals while attending online classes and assessment, EFL learners face difficulties because of insufficient logistic support, unaffordable devices, internet services, unavailability of class materials, interrupted internet connection, noisy home environment, incessant reading from online materials, lack of scope in developing language skills, and struggling to participate in online assessment.

This study finds the dangerous mental health condition that the ELT teachers face because of sudden dependency on online without any prior knowledge, fear of losing a job, sudden extra fare, and lack of computer literacy, which have increased their workload worsening mental health condition. It also shows how making a balance between professional life and personal life by staying at home leads to deteriorating their mental health condition during this pandemic. The investigated result will show the path for future researchers to do more research on the teachers and students' mental health from the participants of other areas.

\section{Recommendations}

Finally, yet importantly, the uncertainty and fear surrounding the current pandemic have given rise to anxiety, stress, and various mental health issues that have also befallen ELT teachers and EFL learners. They are under enormous psychological pressure like the rest of society. They also have their relatives or friends infected with this deadly virus or fighting on in the death bed. Even if not infected or suffered fatalities, the COVID-19 has created enough trepidations and hence overwhelming people of all levels. Every individual has a fear of death. Amidst this, it is almost impossible for teachers and students to concentrate on either teaching or to study thoroughly.

Regardless of the pandemic, most occurrences evoking psychological distress can be diminished by well-constructed and lenient approaches and solutions. Such a huge population could be engaged in online education after careful observation and planning. Culturally relevant pedagogy with mini-lessons can keep both teachers and learners interactive. Nowadays, Microsoft and many other web developers provide efficient tools for e-Learning like zoom, Google Meet and many others. However, learning through eLearning apps may increase fatigue among teachers and students, which should be measured under consideration.
Providing video recordings of the online class lectures would help them to refer to the videos later. They can watch it multiple times or even offline after downloading, to clear concepts chapter wise. As stated by Islam et al. (2020), adopting a "universal pass" for the current semester so that no student would fail irrespective of their academic performance, and get relief from worries. The government should also come forward and take some actions to seriously consider providing subsidy for education using the internet without disruption similar to other sectors which have received aids during COVID-19.

\section{References}

Afacan Adanır, G., İsmailova, R., Omuraliev, A., \& Muhametjanova, G. (2020). Learners' Perceptions of Online Exams: A Comparative Study in Turkey and Kyrgyzstan. International Review of Research in Open and Distributed Learning, 21(3), 1-17.

Avi Bessera. A., Lotem. S. \& Zeigler-Hill. V. (2020). Psychological Stress and Vocal Symptoms among University Professors in Israel: Implications of the Shift to Online Synchronous Teaching during the COVID-19 Pandemic, Journal of Voice. In Press. DOI: 10.1016/j.jvoice.2020.05.028

Banna. M. H. A., Sayeed. A., Kundu. S., Christopher. E., Hasan. M. T., Begum. M. R., Kormoker. T., Dola. S. T. I., Hassan. M. M., Chowdhury. S., Khan. M. S. I. (2020). The impact of the COVID-19 pandemic on the mental health of the adult population in Bangladesh: a nationwide cross-sectional study. International Journal of Environmental Health Research. In press 1-12. DOI: 10.1080/09603123.2020.1802409.

Chowdhury, A. (2020, June 04). Online classes in the time of coronavirus. The Daily Star. Retrieved from:

https://www.thedailystar.net/shout/news/online -classes-the-time-coronavirus-1908393

Dhawan. S. (2020). Online Learning: A Panacea in the Time of COVID-19 Crisis. Journal of Educational Technology. 49(1). 5-22. DOI: $10.1177 / 0047239520934018$

Hasan, M. T., Hossain, S., \& Safa, F. (2020). Immediate psychological responses during the initial period of the COVID-19 pandemic among Bangladeshi medical students. PsyArXiv. DOI: 10.31234/osf.io/9fdu2

Hossain, K. A., Roy, S., Ullah, M. M., Kabir, R., \& Arafat, S. Y. (2020). COVID-19 and Mental Health Challenges in Bangladesh. Advances in Medical, Dental and Health Sciences, 3(2). 
Islam, K. M. A., \& Bhuiyan, M. S. S. (2020). Growing Importance of ICT in ELT for Effective Pedagogy during COVID-19 Pandemic in Bangladesh. Journal of ELT and Education, 3(3). 106-115.

Islam, M.S., Tanvir, KM., Amin \& M., Salman, M. (2020). Online classes for university students in Bangladesh during the Covid-19 pandemic- is it feasible?. The Business Standard. Retrieved from: https://tbsnews.net/thoughts/onlineclasses-university-students-bangladesh-duringcovid-19-pandemic-it-feasible-87454

Islam, S. M. D., Doza., B., Khan. R. M., Haque, A. \& Mamun, M. A. (2020). Exploring COVID-19 stress and its factors in Bangladesh: A perception-based study. Heliyon. 6. DOI: 10.1016/j.heliyon.2020.e04399

Khan, A. H., Sultana, M. S., Hossain, S., Hasan, M. T., Ahmed, H. U., \& Sikder, M. T. (2020). The impact of COVID-19 pandemic on mental health \& well-being among home-quarantined Bangladeshi students: A cross-sectional pilot study. Journal of affective disorders, 277, 121128. DOI: 10.1016/j.jad.2020.07.135.

Mishra, L., Gupta, T., \& Shree, A. (2020). Online teaching-learning in higher education during lockdown period of COVID-19 pandemic. International Journal of Educational Research Open, $1, \quad 100012 . \quad$ DOI: 10.1016/j.ijedro.2020.100012

Mondol, M. S., \& Mohiuddin, M. G. (2020). Confronting Covid-19 with a Paradigm Shift in Teaching and Learning: A Study on Online Classes. International Journal of Social, Political and Economic Research, 7(2), 231247.

Mowbray, H . 2020. In Beijing, coronavirus 2019nCoV has created a siege mentality. BMJ. 368. DOI:10.1136/bmj.16968.

Murphy. M. P. A. (2020) COVID-19 and emergency eLearning: Consequences of the securitization of higher education for post-pandemic pedagogy, Contemporary Security Policy, 41:3, 492-505,

DOI: $10.1080 / 13523260.2020 .1761749$

Peter D., MacIntyre. P. D., Gregersen. T., Mercer. S. (2020). Language teachers' coping strategies during the Covid-19 conversion to online teaching: Correlations with stress, well-being and negative emotions. Vol 94. DOI: $.1016 /$ j.system.2020.102352

Priyo, A.K.K., Hazra, U. (2020, May). What students think about online class and assessment in private universities. The Daily Star. Retrieved from: https://www.thedailystar.net/opinion/news/wh at-students-think-about-online-class-andassessment-private-universities-1900060

Radha, R., Mahalakshmi, K., Kumar, V. S., \& Saravanakumar, A. R. (2020). E-Learning during lockdown of Covid-19 pandemic: A global perspective. International journal of control and automation, 13(4), 1088-1099.

Satu, M., Howlader, K.C., Islam, S.M.S., 2020. Machine learning-based approaches for forecasting COVID-19 cases in Bangladesh. SSRN. Epub ahead of print. Saqlain, N. U. \& Islam, R. U. (2014). Motivation in English Language Learning: A Study of English Language Centers in Hyderabad. Journal of Education and Sciences. 2(1), 71-87.

Tasneem, S.T. (2020). Think out of the box to ensure learning continuity. The Daily Star. Retrieved from:https://www.thedailystar.net/opinion/new s/think-out-the-box-ensure-learningcontinuity-1898287

U.S. Department of Health \& Human Services. (2020, May 28). What Is Mental Health? Retrieved from: https://www.mentalhealth.gov/basics/what-ismental-health

Usman, N., Mamun, M.A., Ullah, I., 2020. COVID-19 infection risk in Pakistani healthcare workers: the cost-effective safety measures for developing countries. Soc. Health Behav. 3 (3), 75-77.

World Health Organization. (2020). WHO DirectorGeneral's statement on IHR emergency committee on novel coronavirus (2019-nCoV). Retrieved from: https :/www.hoint/dg/speec hes/detai 1/who-direc tor-gener al-s-state menton-ihr-emerg ency-commi ttee-on-novel -coron avirus-(2019-n

Yeasmin, S., Banik, R., Hossain, S., Hossain, M. N., Mahumud, R., Salma, N., \& Hossain, M. M. (2020). Impact of COVID-19 pandemic on the mental health of children in Bangladesh: A cross-sectional study. Children and youth services review, 117, 105277.

Zayapragassarazan Z. (2020) COVID-19: Strategies for Online Engagement of Remote Learners . Retrieved from https://doi.org/10.7490/f1000research.1117835 .1 